\title{
A Ética e a Moral em
}

\section{anestesiologia veterinária}

- Ethics and morals in veterinary anesthesiology

\section{- La ética y la moral en anestesiología veterinaria}

\author{
* Flávio Massone CRMV-SP - nº263
}

* Professor Titular Voluntário de Anestesiologia Veterinária do Departamento de Cirurgia e Anestesiologia da Faculdade de Medicina Veterinária e Zootecnia da UNESP, Campus de Botucatu e Professor Titular de Anestesiologia da Faculdade de Medicina Veterinária da Fundação de Ensino Octávio Bastos, São João da Boa Vista,SP.

\section{RESUMO}

O autor define Ética e Moral e, após três décadas de experiência profissional, discute a Moral e a Ética nas atividades de pesquisa, didáticas e de extensão, observando as possíveis distorções que ocorrem, sugerindo a conduta técnica e ética que deve ser tomada em cada circunstância, citando autores antigos como Hipócrates e René Descartes.

Palavras-chave: Ética. Moral. Didática. Pesquisa e extensão.

$\underline{\mathrm{N}}$

a Declaração de Helsinque I, adotada na $18^{\mathrm{a}}$ Assembléia Médica Mundial, em Helsinque, Finlândia (1964), o item nº1 dos Princípios Básicos enuncia: "A pesquisa clínica deve adaptar-se aos princípios morais e científicos que justificam a pesquisa clínica e deve ser baseada em EXPERIÊNCIAS DE LABORATÓRIO E COM ANIMAIS".

A Declaração de Genebra, da Associação Médica Mundial, estabelecia o compromisso do médico com as seguintes palavras: "A saúde do meu paciente será minha primeira consideração”.

Segundo Goldemberg (2000), a Lei Judaica proíbe crueldade para com os animais, que devem ser tratados humanamente, com bondade e compaixão. Ain- da, conforme essa mesma Lei, experiência com animais é somente permitido se for realizada para o bem da Humanidade e não simplesmente para satisfazer desejos individuais, preceitos que estão em Êxodus (23:5) e em Deuteronômio (25:4). O Judaísmo adota também o conceito em que tudo criado neste mundo por Deus foi criado para servir a Humanidade.

Segundo Vieira e Hossne (1998), o conceito de Moral e o de Ética, para algumas pessoas, são praticamente sinônimas, quando isto, a saber, é uma inverdade. Segundo os autores, Ética advém do grego éthike e implica julgamento e está relacionada à avaliação do comportamento humano, enquanto que Moral deriva do latim, mos, moris, implicando conformidade com 


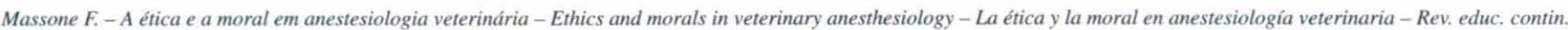

os padrões de comportamento aceitos por uma sociedade numa determinada época.

Apesar da estreita relação entre Moral e Ética, pode-se estabelecer que Moral é algo inato e obedece a critérios de honestidade, justiça e perfeição, buscando sempre os bons costumes, visando sempre aos melhores procedimentos, ou seja, buscando o conjunto de qualidades que não agridam o conceito básico de filosofia de vida.

O conceito de Moral, atrás de si, guarda um conteúdo que se vem alterando através dos séculos e que varia segundo os valores de cada sociedade, portanto, muitas vezes, um padrão moral de um esquimó pode variar quando confrontado com um de um neolatino, o que em nada altera o conceito básico de Moral.

Já o conceito de Ética fundamenta-se em regras, logo, envolve julgamentos que, quando postos em prática, requerem justificativas, buscando o porquê do afastamento dos princípios básicos preestabelecidos.

A partir dessa apresentação conceitual, é necessário fazer um estudo e uma fundamentação destes predicados na Anestesiologia Veterinária para que não haja subliminarmente um conceito de "vale-tudo" para salvaguardar mais os interesses dos profissionais equivocados ou até despreparados, buscando apenas na profissão o conceito de mero atendimento ou, ainda, mais uma aula dada ou "pesquisa de rotina".

A pesquisa em Anestesiologia Veterinária, em nosso País, praticamente encetou em 1946 na Faculdade de Medicina Veterinária da Universidade de São Paulo, com o Prof. Ernesto Antônio Matera. Hoje, no terceiro milênio, já existe uma plêiade de profissionais que atuam nesta área de tão grande importância e, acima de tudo, humana.

Se nós nos basearmos no princípio de Virgílio, que cita "Sedare dolorem opus, divinum est", ou seja, sedar a dor alheia é uma coisa divina, veremos que a Anestesiologia cinge-se de importância especialmente quando, em primeiro lugar, pensa-se naquele que pacientemente submete-se às nossas manipulações, cruentas ou não, daí o nome de "paciente".

Para que se possa fazer uma análise lógica da Ética em Anestesiologia Veterinária, é necessário que se faça uma análise da sua evolução nas últimas três décadas, observando como ela evoluiu, sem buscar o culto às personalidades ou às escolas.

As técnicas existentes, em quase todas as escolas de veterinária, até 1970, eram:

\section{Pequenos animais}

\section{Anestesias locais}

Procaína a 1 e $2 \%$ e início do uso da lidocaína ou lignocaína

\section{Tranqüilizações \\ Clorpromazina.}

Anestesias gerais de ultracurta duração

Tiopental sódico e Tiamilal sódico

Anestesias gerais de média duração

Pentobarbital sódico com a picrotoxina como antagonista.

Anestesia geral volátil

Medicação pré-anestésica: Clorpromazina

Indução: Tiopental sódico

Manutenção: Éter dietílico puríssimo (éter anestésico)

e, em algumas escolas, o éter sulfúrico.

\section{Grandes animais}

\section{Anestesias locais}

Procaína a 1 e $2 \%$ e início do uso da lidocaína ou lignocaína

\section{Tranqüilizações}

Clorpromazina, promazina e prometazina.

\section{"Anestesias gerais"}

Hidrato de cloral + sulfato de magnésio + tiopental sódico

\section{Anestesia geral}

Clorpromazina -Tiopental sódico + Éter dietílico puríssimo

\section{Emprego do halotano, surgido em 1961}

Técnica e eticamente seria difícil avaliar esses procedimentos anestésicos, a não ser o uso do éter sulfúrico, que poderia ser considerado antitécnico e antiético, pois seu uso restringia-se às eutanásias em massa para ratos, camundongos e cobaias dentro das campânulas.

A fim de que se possa analisar eticamente a Anestesiologia Veterinária, seria interessante dividi-la em três tópicos diferentes, a saber: 
1. Anestesiologia no Ensino

2. Anestesiologia na Experimentação/Pesquisa

3. Anestesiologia na Extensão (atendimento à comunidade)

\section{A Ética no ensino}

Já se foi o tempo em que se usavam vários animais para ensaios de técnica cirúrgica, utilizando-se obviamente da anestesia, e, em ato contínuo, após a cirurgia, o aluno responsável pela anestesia, era chamado, sem uma conscientização prévia, para sacrificar os animais, o que causava constrangimento. Em contraposição, havia os recalques emocionais daqueles mais "valentes" que executavam o ato sem qualquer "remorso".

Respeitando o Código de Ética, sabe-se que os procedimentos que submetem os animais a manipulações cruentas em atividades agudas, seguidas de seqüestros orgânicos (esplenectomias, gastrectomias, enterectomias, nefrectomias e outras), devem ser precedidos de anestesia geral barbitúrica (pentobarbital sódico) ou anestesia volátil (halogenados) acompanhadas do controle de sua profundidade, mediante protocolos anestésicos.

Hoje, nota-se em certas instituições de ensino, talvez por comodismo ou até por desconhecimento, a prática da anestesia geral com barbitúricos de ultracurta duração para as aulas de técnica cirúrgica. Nesse caso, esse tipo de anestesia é considerada antiética, caso o animal permaneça vivo, porque as cirurgias de aprendizado são demoradas em razão da falta de destreza do aluno, demandando prolongamentos consecutivos da anestesia, que possui efeito cumulativo, ou seja, há aumento do período hábil anestésico, com recuperação tardia do animal, desconfortável e desagradável de ser vista.

Existe a necessidade do uso de tantos animais no ensino da Anestesiologia e da Técnica Cirúrgica em Medicina Veterinária?

Sabe-se, hoje, que os movimentos contra a eutanásia em animais, que surgiram na Europa, têm crescido e estão alastrando-se pelo mundo inteiro.

Seria difícil hoje sacramentar o não uso de animais nestas áreas, assim como mais difícil seria ainda afirmar que se deve ter o uso ilimitado ou "à vontade" de animais capturados na rua "a bem do ensino". Ambas as afirmativas são errôneas, pois nelas nota-se um extremismo ou até uma hipocrisia cultural, fundamentada, na verdade, pelo nosso nível sócio-cultural "em desenvolvimento".
A utilização do material biológico para o ensino hoje deve ser limitada ao estrito necessário, ou seja, no ensino da Anestesiologia Veterinária, não há necessidade de eliminar os animais, porque podem ser reutilizados, quando se respeita o interstício entre uma anestesia e outra e quando são bem tratados em canis individuais, uma vez que a Anestesiologia prima pelo conforto do animal. Há casos em que os animais tornam-se tão dóceis que sempre alguém se habilita para adotá-los, o que requererá a reposição. Assim, com esses procedimentos, do ponto de vista ético, não haverá atitudes lesivas, pois, além de o animal ter servido ao ensino, ainda encontra um espaço na sociedade, convivendo junto ao homem.

Quando o animal é submetido a anestesias consecutivas, intervaladas, não sofre e nem tem seqüelas, pois, se bem cuidado em canis, com solários adequados, poderá ser aproveitado para múltiplos usos, em que sabidamente não será submetido a desconfortos ou constrangimentos desnecessários como, por exemplo, em aulas práticas de semiologia e radiologia. Forma-se, então, uma nova categoria de animais empregados no ensino sem o uso de manipulações lesivas ou eutanásias desnecessárias.

O problema agrava-se quando surge o emprego da Anestesiologia como suporte às aulas de Técnica Cirúrgica, especialmente se o corpo docente não estiver bem preparado.

A nosso ver, leva-se às vezes um prazo de tempo longo (um semestre aproximadamente), ensinandose aos alunos os fundamentos da técnica cirúrgica, que envolve a terminologia, indumentária, instrumentação, tempos fundamentais da cirurgia, nós, suturas, preparo da mesa cirúrgica, postura em sala. Isto dispensa o uso de animais, pois nada mais é do que o preparo do aluno para a destreza e postura cirúrgicas para ingressar numa sala de cirurgia.

Quando o aluno está preparado para tal fim, cabe aos professores fazerem as cirurgias demonstrativas, $o$ que sobremaneira reduzirá o uso de animais. Caso se queira empregar os animais para treino de alunos, sugere-se o emprego correto da anestesia (pentobarbital sódico e ou anestesia volátil que poucos querem usar) desencadeando a demonstração de vários tipos de cirurgias, sacrificando ao final obrigatoriamente o animal.

Como o material biológico empregado é importante, deve-se aproveitar o sangue para prováveis doações e ainda encaminhar o remanescente para a anatomia ou anatomia patológica, evitando assim novos sacrifícios desnecessários. 
Atualmente, em instituições mais desenvolvidas, empregam-se animais preparados para estes fins, ou seja, glicerinados e que podem ser usados várias vezes, ou treino de suturas em peças obtidas em matadouros (sucedâneos).

Em Anestesiologia Veterinária, em aulas que sabidamente ocorrem óbitos dos animais por incompatibilidades anestésicas como, por exemplo, na demonstração da "síncope branca" (incompatibilidade do halotano com a adrenalina), sugere-se, ao fazê-la, a documentação do evento (pois hoje existe uma tecnologia bem desenvolvida em imagens e sons), não sendo necessário sacrificar, assim, num futuro, animais para novas demonstrações.

Ainda, supostamente, inseridas como aulas de aprendizado em Anestesiologia Veterinária e Técnica Cirúrgica, inserem-se movimentos de castração em massa de animais de clientes, de preferência de pessoas "carentes". Este fenômeno ocorre em instituições de ensino cuja relação docente-aluno não é adequada e onde se demonstra oferecer um serviço de extensão velado sob forma de ensino.

Cabe ressaltar que neste ponto existem dois erros éticos, ou seja; aula é aula e extensão é extensão, pois em hipótese alguma deve-se expor um aluno no aprendizado da Anestesiologia e Técnica Cirúrgica com o serviço de extensão. O outro erro ético é de que o aluno nunca pode efetuar um ato cirúrgico sem a participação direta do docente envolvido, fato este que ocorre com freqüência em instituições de ensino despreparadas que se oferecem para efetuar tais intervenções (sob formas de "campanhas") até em recintos não apropriados para um centro cirúrgico.

O ensino da Anestesiologia Veterinária é algo sublime e compete aos docentes bem preparados desenvolver a consciência do ato nos alunos com um preparo sólido dos fármacos a serem empregados, ou seja, prevendo os efeitos colaterais ou possíveis desconfortos, e acima de tudo, no desenvolvimento do ensino, efetuar um protocolo dos atributos fisiológicos, observando-se as alterações paramétricas de cada parâmetro avaliado, ressaltando-se que hoje necessário se faz o emprego, no mínimo, além da temperatura retal, freqüências cardíaca e respiratória, o uso da pressão arterial não invasiva e da oximetria e capnometria.

\section{A Ética na pesquisa Histórico}

A pesquisa em Anestesiologia Veterinária consolida-se a partir da década de 70, pois anteriormente havia trabalhos esparsos sobre o assunto executados por cirurgiões.

Obviamente, as pesquisas nesta área tinham a validade para a época, pois, além de os trabalhos serem mais de observação, por vezes, subjetivos, não obedeciam a uma nômina específica, e tornavam, por assim dizer, o embrião da Anestesiologia Veterinária Experimental.

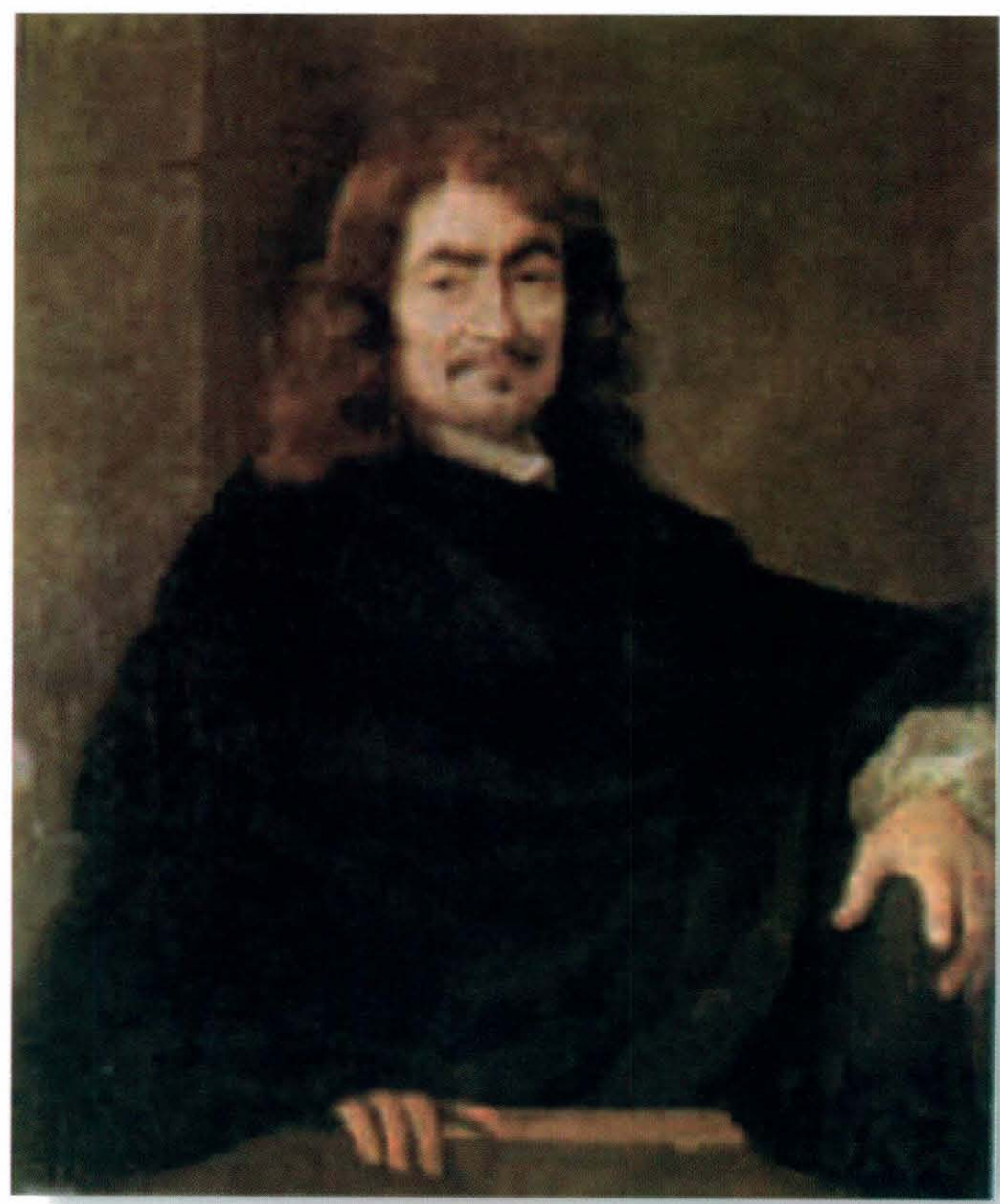

René Descartes de S. Bourdon - Louvre - Paris

*'Touraine, 31 de março de 1596, Estocolmo 11 de fevereiro de 1650
Com o decorrer do tempo, surgem especificamente profissionais que se dedicam exclusivamente à Anestesiologia Veterinária que, sistematicamente, com a pós-graduação dos seus docentes, começam a montar núcleos de pesquisas sustentados pelos órgão financiadores de pesquisas (FAPESP, CAPES e CNPq) 
As pesquisas nesta área inicialmente se desenvolveram pelo pioneirismo de alguns docentes, de maneira isolada, e, posteriormente, houve a agregação de mais pesquisadores e a participação de pós-graduandos, residentes e, até, estagiários bolsistas.

\section{Como surge uma pesquisa?}

Se nos basearmos na frase de René Descartes que dizia: Ego cogito, ergo sum sivo existo, o que quer dizer "Eu penso, logo existo", ode à intuição clara, como faculdade da razão, veremos que, o pesquisador, quando se questiona continuamente, sempre encontrará uma resposta na pesquisa, pois ela é geradora de todo conhecimento que acompanhará, de maneira dinâmica, o ensino e a extensão.

A partir do momento em que o pesquisador encontrou a sua hipótese, ele deve buscar, baseado em literatura prévia, o seu delineamento experimental, buscando na tríade, bem levantada por Vieira e Hossne (1998), em que citam a importância do Respeito, da Beneficência e da Justiça.

\section{Respeito}

Em Anestesiologia Veterinária, em primeiro lugar, devemos ter o respeito pelo animal de experimentação, prescindindo de nosso conforto e buscando o conforto do paciente.

A equivalência desse termo refere-se justamente à reflexão do pesquisador em não causar dor desnecessária nem desconfortos que não possam ser contornados, quer com fármacos, quer com os métodos práticos que os aliviem; por exemplo, sabendo-se que a anestesia causa uma hipotermia, para que deixar um animal em cima de uma mesa de aço inoxidável, (porque é mais higiênica) ou o ar condicionado ligado (porque dá o bem estar ao pesquisador), quando existem alternativas que contornam estes problemas?

O tratamento dos animais com todos os métodos de contenção preventiva (mordaça em cães) não proíbe que os pesquisadores tranqüilizem o cão ou, às vezes, com um simples gesto de carinho, o contenha, lembrando que, no fim do experimento, quando existe o restabelecimento pleno das grandes funções do animal, levaria a uma pergunta básica: por que não reconduzilo ao seu canil ao invés de esquecê-lo na jaula de recuperação?

\section{Beneficência}

O princípio que diz: “Primum non nocere”, ou seja, primeiramente não cause dano, é real. O fato de gerar o bem-estar ao animal de experimentação, torna a pesquisa mais qualificada, pois afasta boa parte da interferência do estresse, causado pelo próprio pesquisador, além de trazer novos conhecimentos no interrelacionamento pesquisador $\mathrm{x}$ animal.

\section{Justiça}

Baseados nos conceitos emitidos por Vieira e Hossne (1998), o conceito de justiça exige que a distribuição de danos e benefícios seja justa. Extrapolando para a experimentação animal é necessário que dentro do seu delineamento experimental, sejam demonstrados não apenas os resultados de sucesso ou positivos de uma pesquisa científica, mas também os negativos, como, por exemplo os casos de paralisia peniana em garanhões quando se utiliza a acepromazina, que apesar de raros, já foram descritos na literatura científica.

No nosso meio, a maioria dos casos de evolução negativa são ocultados, quando, em sã consciência, deveriam ser descritos, buscando até uma solução adequada para que não houvesse, no futuro, repetições.

Por outro lado, é frequiente a conduta injusta de o pesquisador, ao estabelecer um grupo de tratamento específico e observar um dado destoante dos demais, simplesmente retirar o animal do grupo e substituí-lo por um "que deu certo"; isto seria a mesma coisa que "jogar a sujeira embaixo do tapete". Ainda como distorção, cita o emprego de animais "clinicamente sadios”, quando, na verdade, a sua amostra já está viciada, pois os valores de hemoglobina estão tão baixos que $\mathrm{o}$ animal não pode ser submetido à anestesia.

\section{Quem pode desenvolver a pesquisa?}

A Lei Federal no 6.638 de 8 de maio de 1979 estabelece critérios e normas para vivissecção em animais, proibindo-a nas seguintes condições: sem emprego da anestesia, em centros de pesquisas e estudos não registrados em órgão competente, sem supervisão de técnico especializado, com animais que não tenham permanecido mais de 15 dias em biotérios legalmente autorizado, em estabelecimentos de ensino de primeiro e segundo graus e em quaisquer locais frequentados por menores (Art. $3^{\circ}$ incisos I e V, da referida lei)." 


\section{Quais são os preceitos básicos de um pes- quisador?}

Obviamente, um pesquisador não se forma de imediato, pois primordialmente deve estar munido de moral e ética, além do preparo científico, acompanhado de maturidade científica e conceito humanitário.

O mundo da pesquisa é um caminho com muitos empecilhos, em que se leva, às vezes, anos para se conseguir um resultado positivo, ou não, transmitido em poucos minutos.

\section{Como um pesquisador em anestesiologia experimental deve proceder?}

Quando um pesquisador começa a pesquisar, inicialmente deve ter a competência suficiente de avaliar os riscos e danos que a sua pesquisa pode gerar, bem como quais os benefícios que a coletividade científica poderá obter, a fim de evitar desperdícios desnecessários de animais experimentais.

Além disso, obedecendo ou não avaliações estatísticas, o pesquisador poderá aquilatar o valor da sua amostra, isto vale dizer que, se ao usar um fármaco que cause a morte do animal e ao repetir o experimento, observar mais óbitos, não é necessário obedecer a estatística que recomenda que a amostra seja $n=10$.

O bom senso do pesquisador delimitará o número de animais necessários e suficientes para que, com segurança, se evitem mortes desnecessárias.

Em centros de pesquisas mais desenvolvidos, existem Comissões de Ética que previamente avaliam o delineamento experimental, a ponto de não permitir a evolução do trabalho, caso não seja aprovado no seu lídimo aspecto ético.

Um pesquisador, antes de encaminhar o seu delineamento experimental para julgamentos superiores, deve obrigatoriamente estabelecer certos critérios em sua pesquisa, tais como:

- Após a informação completa dada ao proprietário, obter o seu consentimento ao se tratar de pesquisa de âmbito hospitalar;

- Apresentar metodologia adequada, ou seja, não abusar dos métodos lesivos, sem antagonizá-los;

- Evitar manter o animal anestesiado desnecessariamente apenas porque o seu "tempo parasita" é extenso. Aliás, esta prática é muito freqüente e será abordada com mais detalhes no tópico Ética na extensão;

- Programar o período certo da pesquisa, evitando o acúmulo de animais dentro de uma sala de Anestesiologia Experimental, pois a quietude neste recinto é de vital importância;

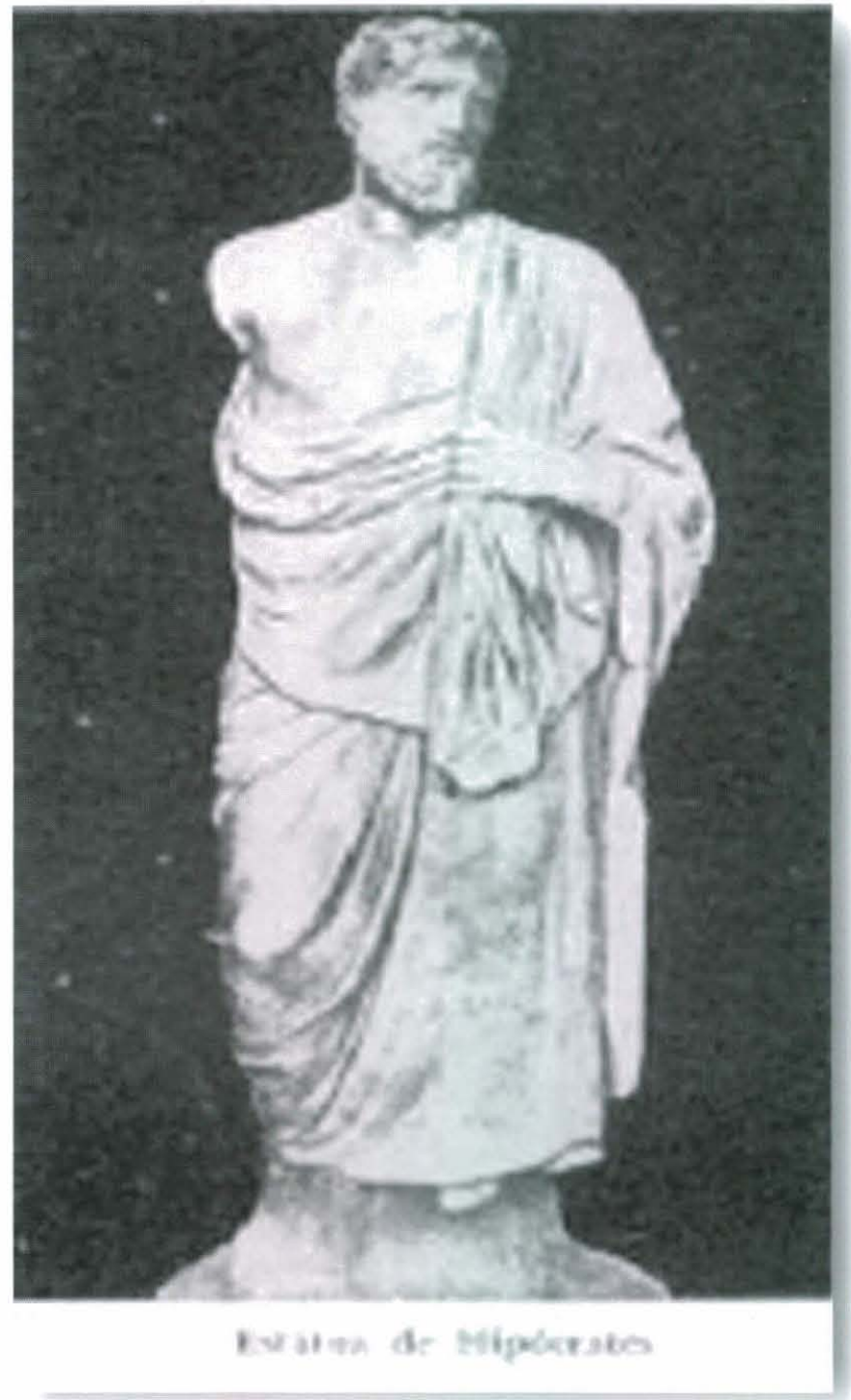

"Ciência e Opinião são duas coisas distintas, pois enquanto a primeira

- Buscar e promover o conforto dos seus animais, oferecendo fármacos anestésicos cujas características gerem a menor alteração paramétrica ou aprimorar o meio de aquecimento quando sabidamente, durante o experimento, ocorrerá uma hipotermia;

- Evitar o trânsito de pessoal despreparado numa sala de experimentação, especialmente se o paciente estiver desperto, provocando-lhe um estresse desnecessário, além de causar confusão no ambiente;

- Ao término da pesquisa, evitar terceirizar tarefas, que geralmente redundam em esquecimento do animal, levando-os, às vezes, a um segundo jejum (pósexperimento), desnecessário;

- Envolver, na sua pesquisa, pessoal preparado, orientando a equipe e não "deixar correr a pesquisa" na 
Massone F. - A ética e a moral em anestesiologia veterinária - Ethics and morals in veterinary anesthesiology-La ética y la moral en anestesiología veterinaria - Rev. educ. contin. CRMV-SP / Continuous Education Journal CRMV-SP. São Paulo, volume 5, fascículo 1, p. 124 - 133, 2002

mão de pessoal "flutuante" (estagiários ou pessoas efêmeras).

Apesar destas dificuldades, a carreira do pesquisador é gratificante e encontra respaldo na célebre frase de Hipócrates (450 a.C.), que dizia: Ciência e Opinião são duas coisas distintas, pois enquanto a primeira expressa inteligência, a segunda ignorância.

Atualmente todas as entidades financiadoras de pesquisa voltadas para o homem ou animais, submetem os pedidos à Comissão de Ética. Existem cursos de pós-graduação que não permitem a defesa de dissertação ou tese de doutorado se o projeto não for submetido à avaliação de uma Comissão de Ética em Experimentação Animal, o que leva a crer que já existe uma conscientização de que o animal necessita não só de amor mas também de respeito.

Ninguém erra porque quer errar. Não sabe que está errando. Erra por desconhecimento e por despreparo técnico. O Colégio Brasileiro de Experimentação Animal-COBEA, entidade filiada ao INTERNATIONAL COUNCIL FOR LABORATORY ANIMAL SCIENCE (ICLAS), procurando aprimorar as condutas dirigidas à experimentação animal no País, postula:

Artigo $1^{\circ}$. Todas as pessoas que pratiquem a experimentação biológica devem tomar consciência de que o animal é dotado de sensibilidade, memória e que sofre sem poder escapar à dor;

Artigo $2^{\circ}$. O experimentador é moralmente responsável por suas escolhas e por seus atos na experimentação animal;

Artigo $3^{\circ}$. Procedimentos que envolvam animais devem prever e se desenvolver considerando-se sua relevância para a saúde humana o animal, a aquisição de conhecimentos ou o bem da sociedade;

Artigo 4. ${ }^{\circ}$. Os animais selecionados para um experimento devem ser de espécie e qualidade apropriadas e apresentar boas condições de saúde, utilizandose o número mínimo necessário e suficiente para se obter resultados válidos. Ter em mente a utilização dos métodos alternativos, tais como modelos matemáticos, simulação por computador e sistemas biológicos "in vitro";

Artigo $5^{\circ}$. É imperativo que se utilizem animais de maneira adequada, incluindo aí evitar o desconforto, angústia e a dor. Os investigadores devem considerar que os processos determinantes de dor ou angústia em seres humanos causam o mesmo em outras espécies, a não ser que o contrário tenha-se demonstrado;

Artigo $6^{\circ}$. Todos os procedimentos com animais, que possam causar dor ou angústia, precisam-se desenvolver com sedação, analgesia ou anestesia adequadas. Atos cirúrgicos ou outros atos dolorosos não podem se implementar em animais não anestesiados e que estejam apenas paralisados por agentes químicos e/ou físicos;

Artigo $7^{\circ}$. Os animais que sofrem dor ou angústia intensa ou crônica, que não possam se aliviar e os que não serão utilizados devem ser sacrificados por método indolor e que não cause estresse;

Artigo $\mathbf{8}^{\circ}$. O uso de animais em procedimentos didáticos e experimentais pressupõe a disponibilidade de alojamento que proporcione condições de vida adequadas às espécies, contribuindo para sua saúde e conforto. O transporte, a acomodação, a alimentação e os cuidados com os animais criados e usados para fins biomédicos devem ser dispensados por técnico qualificado;

Artigo $9^{\circ}$. Os investigadores e funcionários devem ter qualificação e experiência adequadas para exercer procedimentos em animais vivos. Deve-se criar condições para o seu treinamento de trabalho, incluindo aspectos de trato e seu uso humanitário dos animais de laboratório.

\section{A Ética nas atividades de extensão}

As atividades de extensão podem ser divididas em duas partes distintas:

- Atividades de extensão supervisionadas por docentes ou profissionais;

- Atividades de extensão diretamente executada por profissionais.

\section{Atividades de extensão supervisionadas por docentes ou profissionais}

Os docentes ou profissionais que atuam nesta área e no ensino da Anestesiologia Veterinária devem sempre ter em mente que as atividades de formação exigem, acima de tudo, um conhecimento profundo dos conceitos básicos e filosóficos da Anestesiologia.

Enganam-se aqueles que transferem apenas conhecimentos rudimentares da anestesia para os seus aprendizes, pois isto seria o predomínio da revelação sobre a razão.

Por diversas vezes, ao se associar o ensino da Anestesiologia à da Patologia Cirúrgica, pois ambas estão estritamente relacionadas, nota-se, em profissionais despreparados, a demora na atividade cirúrgica ou anestésica. 


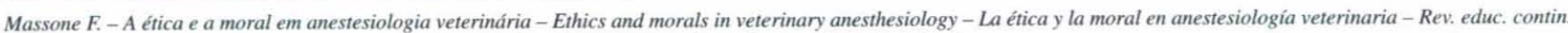
CRMV-SP / Continuous Education Journal CRMV-SP. São Paulo, volume 5, fascículo 1, p. 124 - 133, 2002

Convém esclarecer que não se deve confundir tempo necessário cirúrgico, que varia de minutos a horas, com "tempo parasita" cirúrgico, que é aquele em que o cirurgião não tem habilidade para agilizar o ensino, alegando que o importante é fazer bem feito, esquecendo que o paciente não tem culpa da demora do ato. Isto geralmente é causado por narcisismo profissional ou por despreparo para o ensino em que o responsável ministra verdadeiras aulas teóricas inseridas num ato cirúrgico. Acresça-se a isso, a ausência de materiais considerados essenciais durante $\mathrm{o}$ ato cirúrgico ou a falta de destreza ou habilidade. Analisando com serenidade, observa-se que a destreza é necessária em cirurgia e anestesia; ela deve estar presente e deve ser cobrada continuamente pelos profissionais responsáveis pela formação dos neófitos. Já a habilidade surge no decorrer do tempo, motivo pelo qual o profissional que conduz os trabalhos, quer o anestesista, quer o cirurgião, tem a responsabilidade ética de modular esses períodos, e ser o parâmetro de conduta.

A obrigação de um docente ou de um profissional, pois ambos têm a missão formadora, é de, em hipótese alguma, permitir que o acadêmico execute um ato anestésico ou cirúrgico sem o respaldo direto do médico veterinário, que responde legalmente por tais atos.

Por outro lado, é de competência estrita dos docentes ou do profissional, suspender as cirurgias em caso de transgressão ética durante o evento, o que vale dizer que, ao se realizar uma ovário-salpingohisterectomia, caberá a eles, ao notarem prenhez, suspender imediatamente a intervenção.

Especificamente, neste caso, notam-se dois erros, ou seja, primeiramente toda cirurgia requer exame prévio, o que permitiria a constatação da prenhez; secundariamente, não cometer o erro ético ao tirar vidas, pois a todo profissional compete deliberar sobre a vida do paciente, mas não lhe compete tirar a vida deliberadamente.

Estes orientadores são incumbidos de função primordial, uma vez que devem ter o conhecimento profundo de qual a anestesia mais propícia para a intervenção cirúrgica proposta, pois eticamente não se pode aceitar o emprego de anestesias com atividade somática para abrir cavidade abdominal ou pleural, mesmo que o pretexto seja de que a cirurgia será rápida, ou, ainda, "vamos dar um opióide, para que o animal não sinta", atitude esta confortável para o cirurgião ou anestesista e extremamente desumana para o paciente.

A melhor intervenção cirúrgica é aquela em que a anestesia começa imediatamente antes da cirurgia e se encerra imediatamente após, resguardadas as devidas proporções.

Toda vez que esta norma ética for desobedecida surgirá, além do descontrole da equipe, o desconforto e o sofrimento do animal.

\section{Atividades de extensão diretamente desen- volvidas por profissionais}

A responsabilidade profissional, para quem tem atividade de atendimento em clínicas ou hospitais veterinários, é grande.

Tem-se notado que, com o crescimento exagerado de escolas de Medicina Veterinária, desprovidas de corpo docente apropriado para o ensino prático da Anestesiologia e para as práticas cirúrgicas, têm crescido os casos de anestesias impróprias e se verificado ausência de destreza e habilidade cirúrgica. Há de salientar que, ao se desconhecer tais práticas, o profissional aventura-se nas atividades anestésicas, efetuando anestesias estereotipadas, não considerando, assim, as condições do paciente.

Muitos profissionais preferem correr o risco anestésico em pacientes de alto risco (idosos, anêmicos, caquéticos, obesos ou prenhez) a empregarem técnicas anestésicas mais seguras, como a anestesia volátil, alegando elevação dos custos, como se o paciente fosse responsável pelas nossas restrições econômicas. Cabe salientar que o juramento profissional, quando da colação de grau, deve permanecer íntegro e não se deve mascará-lo com frases facilmente pronunciáveis, e, em tom bombástico, "Infelizmente o animal não agüentou a anestesia" e não se revelando a verdadeira explicação. Ademais, um animal não vai ao hospital para passeio, pois, além do estresse da manipulação, existe a agressão cirúrgica, a "intoxicação temporária" anestésica e todo o envolvimento ligado à própria patologia.

O que muito profissional esquece é que, sob o pretexto de montar uma clínica veterinária, monta colateralmente um verdadeiro hospital veterinário velado e, mesmo assim, desprovido de profissionais que possam constituir uma equipe, isto quando não se nota manifestações de verdadeiras "blagues" em que se nota um exibicionismo antiético, ao se vantar de que fez "tudo sozinho". A conclusão a que se chega é de que, além da conduta profissional inadequada, demonstra o despreparo, a posição antiética e o risco do "ensino" para futuros estagiários que, infelizmente, continuarão no seu despreparo profissional.

Na correção desta situação, cabe às Universidades, quer públicas, quer privadas, a obrigação, por 
Massone F. - A ética e a moral em anestesiologia veterinária - Ethics and morals in veterinary anesthesiology - La ética y la moral en anestesiología veterinaria - Rev. educ. contin. CRMV-SP / Continuous Education Journal CRMV-SP. São Paulo, volume 5, fascículo 1, p. 124 - 133, 2002

seu corpo docente bem preparado, de oferecer cursos práticos e teóricos de atualização, saindo um pouco das suas "muralhas" acadêmicas, participando, assim, da conscientização profissional, pois a elas cabe o dever de discutir as condutas de maneira prática, filosófica e ética, pois não podem esquecer que formarão, no futuro, profissionais que estarão na mesma situação.

\section{Como é que a lei se manifesta?}

Goldemberg (2000) cita a existência da Lei Federal n 6.638, de maio de 1979, que "Estabelece normas para a prática didático-científica da vivissecção de animais e determina outras providências" e que, até hoje, decorridos mais de 20 anos, não foi regulamentada e implantada. Tramita no Congresso Nacional o anteprojeto que "dispõe sobre a criação e o uso de animais para atividades de ensino e pesquisa". Surgiu na Câmara Federal o Projeto de Lei n ${ }^{\circ} 1.153 / 95$, que ameaça a realização de pesquisas em animais. Os Estados Unidos levam muito a sério o uso dos animais para ensino e pesquisa. Muito bem, na leitura de um artigo cujo autor afirma ter seguido aquelas normas, ao se ler o método, o investigador deixa evidente que não cum- priu as normas. Assim também no que concerne às $R e-$ ferências (ABNT/ISO/ou VANCOUVER), que constam nas Instruções, mas não as cumprem, nem os autores e nem o Editor da Revista. Estes artigos são devolvidos.

Diante destas circunstâncias, urge que primeiramente se conscientize os pesquisadores de que o melhor trabalho não é só aquele que apresentou os melhores resultados, mas, sim, aquele que apresentou bons resultados sem causar o malefício (dor, desconforto, subjugação desnecessária) aos animais de experimentação e foi executado dentro dos princípios básicos de Ética e Moral.

Em segundo lugar, cabe às próprias instituições ou mesmo Diretorias Científicas dos Colégios, Congressos, Comissões julgadoras, Fundações financiadoras de pesquisa, Universidades, negarem financiamentos ou mesmo publicações de trabalhos considerados antiéticos, pois somente assim aprenderemos a respeitar a máxima de Leonardo da Vinci:

“CHEGARÁ O DIA EM QUE O HOMEM CONHECERÁ O ÍNTIMO DOS ANIMAIS E, NESTE DIA, O CRIME CONTRA O ANIMAL SERÁ CONSIDERADO UM CRIME CONTRA A HUMANIDADE"

\section{SUMMARY}

Based on thirty years of professional experience, the author defines and discusses Ethics and Morals in settings such as research, teaching and extension activities. Considering distortions that can occur, suggestions are made about the technical and ethical procedures to be implemented in each situation. Authors as Hipocrates and René Descartes are quoted.

Key words: Ethics. Morals. Teaching. Research. Extension.

\section{RESUMEN}

El autor define Ética y Moral y, después de tres décadas de experiencia profesional, discute la Moral y la Ética en las actividades de investigación, didáctica y extensión, observando las posibles distorsiones que ocurren, sugiriendo la conducta técnica y ética que se debe adoptar en cada circunstancia, citando autores antiguos como Hipócrates y René Descartes.

Palabras clave: Ética. Moral. Didáctica. Investigación y extensión. 


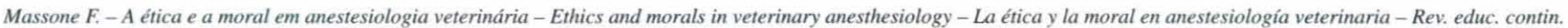
CRMV-SP / Continuous Education Journal CRMV-SP. São Paulo, volume 5, fascículo 1, p. 124 - 133, 2002

\section{REFERÊNCIAS}

GOLDEMBERG, S. Aspectos Éticos da Pesquisa com Animais. Acta Cirúrgica Brasileira, v. 15, n. 4, 2000.

LOPES, O. C. A Medicina no tempo. São Paulo: Melhoramentos, $1970.339 \mathrm{p}$.
MASSONE, F. Anestesiologia veterinária: farmacologia e técnicas. Rio de Janeiro: Guanabara Koogan, 1999. 225 p.

VIEIRA, S.; HOSSNE,W. S. A Ética e a metodologia. São Paulo: Pioneira, 1998. 